\section{A study on the effect of team support and emotional exhaustion on organizational citizenship behavior of nurses in COVID-19 pandemic: mediation by team commitments}

\author{
Prasanjit Dasgupta \\ Faculty of Management and Commerce, ICFAI University Tripura, Agartala, India
}

OCB of nurses in COVID-19 pandemic

Received 21 October 2021 Revised 4 November 2021 26 November 2021

\begin{abstract}
Purpose - Nurses need to display organizational citizenship behavior (OCB) for taking care of patients; uninterrupted care to coronavirus disease 2019 (COVID-19) patients in a stressful situation may result in emotional exhaustion and it hinders nurses' exercise of OCB. One perceives support when positive exchanges with team leaders and members (LMX) and team and members (TMX) take place for the benefit of self and the unit and lead to a feeling of commitment to the work team; the exchange facilitates the discharge of OCB. The study aims to explore the mediation effect of team commitments on the relationship between these factors with OCB of nurses in handling COVID patients.

Design/methodology/approach - The cross-sectional exercise attempts to find the impact of emotional exhaustion, LMX and TMX on the OCB of the nurses and mediating effects of team commitments on OCB; correlation analysis and multiple regressions are in use for examining the relationships. The use of Sobel test and bootstrapping exercise confirm the mediation and consistency of mediation results on a larger sample.

Findings - The paper finds that LMX, TMX and team commitments significantly relate to OCB; emotional exhaustion negatively impacts $\mathrm{OCB}$ and team commitments fully mediate the relationship between emotional exhaustion and OCB and partially mediate the relation between LMX and TMX with OCB.

Originality/value - Tests demonstrate that team commitments can neutralize the effects of emotional exhaustion resulting from handling COVID-19 patients on OCB of the nurses and is an addition to organizational behavior literature. The study also presents a model that shows how positive LMX, TMX and resultant team commitments support generating OCB and offset the impact of emotional exhaustion. Theoretical and managerial implications, limitations and scope for further research discussed in the paper.
\end{abstract}

Keywords OCB, Team commitments, COVID-19 stressors, Emotional exhaustion, LMX, TMX

Paper type Research paper

(C) Prasanjit Dasgupta. Published in IIM Ranchi Journal of Management Studies. Published by Emerald Publishing Limited. This article is published under the Creative Commons Attribution (CC BY 4.0) licence. Anyone may reproduce, distribute, translate and create derivative works of this article (for both commercial and non-commercial purposes), subject to full attribution to the original publication and authors. The full terms of this licence may be seen at http://creativecommons.org/licences/by/4.0/ legalcode

The author gratefully acknowledges the support of the nurses who participated in the study inspite of their busy schedule.

Sources of funding: This is to declare that author did not receive any fund from any individual or institution in connection with the research project.

Author's contribution: The entire work has been done by the author and there is no co-Author in this regard

Conflict of interest: This is to declare that this research is entirely done by the author. There is no conflict of interest with any individual or institution in doing the work.

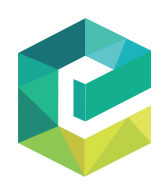

IIM Ranchi journal of management studies Vol. 1 No. 2, 2022 pp. $145-159$ Emerald Publishing Limited e-ISSN: 2754-0146 p-ISSN: $2754-0138$ DOI 10.1108/IRJMS-09-2021-0129 
$\underset{1,2}{\text { IRJMS }}$

\section{Background}

COVID-19 pandemic has threatened human beings throughout the world, including India; healthcare setup became overburdened due to heavy rush of patients; shortage of health workers became an issue as many of them have been tested positive (The Times of India, April 25, 2021).

Nurses form the largest group of health workers and provide round-the-clock care at the bedside of the COVID-19-infected patients (Zhang et al., 2021). They need to exhibit OCB, as often nurses need to perform works that are not within their job description.

Researchers like Sharif-Nia et al. (2021) recommended the voluntary performance of nurses in the COVID-19 pandemic to take care of a heavy load of patients.

Sharma et al. (2020) remarked nurses' OCB during a pandemic with the tasks mentioned in the job description, need to screen the patients, implement triage and provide health education on prevention and protection from the coronavirus.

These have resulted in more frequent communication with other caregivers, more time on equipment and supplies and higher effort on psychological support to relatives of the patients (Sharma et al., 2020).

Shreffler et al. (2020) viewed in this crisis that healthcare workers face challenges to give treatment to COVID-19-infected patients, reduce the spread of infection, develop short-term strategies and generate long-term plans for treatment of these patients.

Organ (1988, p. 4) defined OCB as "Discretionary individual conduct, not directly or explicitly recognized by the formal system of compensation contributing to the general-proper functioning of the organization that does not arise from the prescribed role or tasks of the job".

Thus, apart from performing under specific terms of the contract between employees and organizations, this behavior arises rather from personal choices, and its omission is not generally understood as punishable.

According to Said and El-Shefai (2020), nurses being front line caregiver to the COVID-19 patients may develop emotional and psychological stress due to:

(1) Frequent death and dying of the patients;

(2) Death and dying colleagues and other known health workers;

(3) Continuous work wearing heavy personal protective equipment;

(4) Fear of infection and its spread to family members;

(5) Sometimes remaining out of home for days together and

(6) Encounter rude behavior by panic-stricken patient relations.

Prolonged exposure to stress leads to burnout; the model of Leiter and Maslach (1988) and that of Lee and Ashforth (1993) describes that burnout progresses from emotional exhaustion to that of depersonalization and lack of personal accomplishment.

The above studies consider emotional exhaustion as the first dimension of burnout.

Studies show healthy exchange with the leader in the form of positive LMX enhances the OCB of the nurses during the COVID-19 pandemic (Zhang et al., 2020).

Murat et al. (2020) cited the studies of Wu et al. (2008), saying dependence among healthcare workers increased during and after the SARS pandemic in China.

Sharif-Nia et al. (2021) observe organizational commitments of nurses mediate intention to care for COVID-19-infected patients; Alshabani et al. (2021) report mediation effect of the organizational commitment on OCB of service sector employees during the COVID-19 pandemic.

Caricati et al. (2015) explain most healthcare institutions have some care units; each care unit team consists of doctors, nurses, psychologists, technicians and other allied professionals who collaborate to treat the patients. 
Treatment to the patients admitted in the unit brings the professionals together with a common identity and provides them a sense of self-esteem and knowledge (Caricati et al., 2015).

Identification and affiliation with the team develop into a commitment to it.

Riketta and Van Dick (2005) observe that commitments to the workgroup have more influence on performance than commitments to the organization.

They argue that commitment to the proximal object like workgroup may be more intense than a distant object like organization.

Dasgupta (2020) finds that the mediation effect of team commitments in the generation of OCB is higher than that of affective organizational commitment in a study on Indian nurses.

Some studies on nurses observe the mediation effect of organizational commitment on intention to care for COVID-19 patients (e.g. Sharif-Nia et al., 2021); hardly studies on the influence of team commitment on extra-role behavior of the nurses for the care of the COVID-19-infected patient are available;

Hence the questions arise as follows:

(1) How do team commitments mediate the impact of emotional exhaustion on the $\mathrm{OCB}$ of the nurses in the treatment of COVID-19 patients?

(2) How do team commitments mediate the effect of positive LMX and TMX on the performance of OCB of nurses on COVID-19 patients?

The research aims to find the mediation effect of team commitments on the relationship between emotional exhaustion, LMX and TMX with OCB of the nurses handling COVID-19 patients; this study may help healthcare managers to devise strategies to enhance the OCB of the nurses in dealing with COVID-19 patients.

\section{Review of literature}

Research on healthcare workers showed a high rate of burnout, psychological stress and suicide during the pandemic (Santarone et al., 2020).

Parel et al. (2020) reported nurses attending COVID-19 patients are more stressed than other nurses.

Murat et al. (2020) opined emotional and psychological problems with the high stress of nurses negatively affect their future cognitive functions and clinical decision processes and may fast result in burnout.

Burnout progresses from emotional exhaustion through depersonalization to lack of personal accomplishments (Leiter and Maslach, 1988). Burnout develops due to heavy job demands and a lack of job resources. In job demands and resources theory, Bakker and Demerouti (2007) explained when workers face prolonged, intense job demands without the resources for coping, they may experience a lot of stress and become emotionally exhausted. During a COVID-19 pandemic in an environment of the threat of infection, nurses need to handle more COVID-19 patients than the usual patient-nurse allocation norm due to the heavy load of patients to the hospitals. They often witness the death of colleagues due to infection, remain away from family for days and encounter rude behavior of patient relatives. All these make the job highly demanding for the nurses.

Said and El-Shefai (2020) viewed these demanding situations create emotional and psychological problems for the nurses. Operating under constant psychological and emotional pressure may lead to the emotional exhaustion of nurses.

Murat et al. (2020) viewed nurses who experience emotional exhaustion in dealing with COVID-19 patients start rating negative own professional skills and abilities and develop negative attitudes toward patients. 
IRJMS

1,2

Nurses perform OCB voluntarily for the well-being of COVID-19 patients; in the event of emotional exhaustion, this feeling of inability and negative attitude toward patients may serve as impediments to exercise OCB. Based on it, we hypothesize as follows:

H1. Emotional exhaustion of nurses is negatively related to their OCB in dealing with COVID-19 patients.

Nurses need to have a high degree of interdisciplinary collaboration (Padgett, 2013), as patient care needs a multi-disciplinary approach involving doctors, nurses and technicians (Caricati et al., 2015).

Collaboration between these professionals is essential for producing a better patient outcome for the unit.

Caricati et al. (2015) described collaborative behavior as actions taken by two or more persons as colleagues performing on equal footing.

COVID-19 pandemic has increased the workload and scope of work of the nurses (Sharma et al., 2020), which has enhanced the requirement of more interdependence, collaboration and mutual helping relationship at work.

Since nurses provide round-the-clock bedside care to the patients and work in shifts (Zhang et al., 2021), they have to meet different requirements that may arise from the high workload and critical condition of the COVID-19 patient.

In these situations, they often look for help from others of the unit; in return, the nurses also continue to help others wherever possible. This mutual helping relationship between the colleagues constitutes support under the job demands resources model of Bakker and Demerouti (2007); it motivates the workers to put in extra effort to help others and may prompt nurses to exhibit more OCB in handling COVID-19 patients.

It hypothesizes as follows.

H2. TMX significantly relates to the OCB of the nurses in dealing with COVID-19 patients.

LMX is a social exchange relationship between an employee and immediate supervisor (Graen and Uhl-Bien, 1995; Gotz et al., 2020).

Some researchers (e.g., Cropanzano et al., 2017; Gotz et al., 2020) explained that social exchange involves a series of transactions of resources between two or more parties through the process of reciprocity.

Gotz et al. (2020) explained high LMX promotes open and spontaneous helping relationships that are mutually beneficial and has described LMX as a prominent antecedent of workplace behavior (Gotz et al., 2020).

Support of the supervisor in the form of positive LMX is a job resource under the job demands resources model of Bakker and Demerouti (2007); nurses burdened with a heavy workload in pandemic look for support from the immediate boss and remain ready to work extra to maintain the relationship.

Che et al. (2021) observed that LMX significantly relates to the OCB of the nurses in the pandemic situation.

Following these, it has been proposed as follows:

H3. LMX significantly relates to the OCB of the nurses in a pandemic situation.

Based on the work of Bishop et al. (2000a, b) and Neininger et al. (2010), Schreuder et al. (2017) narrated the following criteria of team commitments:

(1) Acceptance of goals and values of the team that members may accept; 
(2) Willingness to exert considerable effort for the team and

(3) Desire to maintain team membership.

Caricati et al. (2015) explained caring units of hospitals serve as individual units where different health workers like doctors, nurses, technicians, etc. work together for the super-ordinate goal of patients' treatment. Caricati et al. (2015) found a significant relationship between team commitments and the inter-personal collaboration of unit members.

Tajfel's (1978) social identity theory (SIT) described significant emotional involvement of the members to their group membership. Ellemers et al. (1999), based on Tajfel's SIT (1978), opined group commitments enhance when people find the group is of high status. In such cases, the group commitments aspect of social identity reliably mediates the display of ingroup favoritism (Ellemers et al., 1999).

Thus, it can be assumed favorable action in the form of help to team members or walking extra for the interest of the team leader arising out of healthy LMX and TMX is mediated due to team commitments.

Dasgupta (2020) found a significant relation between LMX, TMX and team commitments of Indian nurses and also mediating effect of team commitments on the relationship between these variables and OCB.

Sharif-Nia et al. (2021) revealed that organizational commitment mediates nurses' intention to care for the COVID-19 patients.

Based on these observations, the researcher suggests that team commitments - a form of commitment directed to a closer object team than an organization - may have a mediating effect on the relationship between TMX, LMX and extra-role behavior of nurses in the treatment of the COVID-19 patients:

H4A. Team commitments mediate the relationship between LMX and TMX with OCB in handling COVID-19 patients.

According to group cohesive theory (Lawler et al., 2000), frequent interaction between group members with the objective of own betterment and to reduce uncertainty evokes positive emotion.

Team commitments characterized by the willingness to exert extra effort for other teammates with a desire to maintain team membership may arise out of the cohesive behavior of team members and leaders.

Based on Lawler et al. (2000), author feels that cohesive behavior among the unit members with the aim of self-betterment and reduction of uncertainty can evoke positive emotion toward the unit.

Positive emotions may impact the negative emotions created due to stressors in handling COVID-19 patients.

Caricati et al. (2015) referred to team commitments as an object to which professionals feel integrated and remain determined to pursue their goals.

Based on the SIT of Tajfel, Scheepers and Ellemers (2019) observed that an underlying principle of SIT is that people strive for a positive social identity like a group, and the emotion of individuals is related to group objectives.

Hence, we assume that despite facing hardship due to emotional exhaustion arising out of a pandemic characterized by depletion of emotional and physical resources, the nurses may continue with their OCB toward patients for maintaining the goodwill of the team and their presence in it and suggest.

$H 4 B$. Team commitments mediate the relationship between emotional exhaustion and OCB of the nurses in the treatment of COVID-19 patients. 
IRJMS The following hypothetical model is formed: (Figure 1).

1,2

\section{Methods}

Data were collected from January 7 to April 8, 2021; 500 questionnaires were circulated to the nurses working in three private hospitals of Kolkata, India, serving COVID-19 patients.

Out of 500 nurses, 452 filled questionnaires were useable.

The instruments as follows are used in the study:

\section{Organizational citizenship behavior}

The OCB scale developed by Podsakoff et al. (1990) and Van Dyne et al. (1994) applied.

It comprises seven items, and one needs to respond on a seven-point scale $(6=$ always and $0=$ never).

The analysis showed reliability alpha 0.909 .

\section{COVID-19 stressors}

The researcher used the Middle East respiratory syndrome coronavirus (MERS-COV) staff questionnaire of Khalid et al. (2016).

Analyzing the stressors of healthcare workers due to the MERS-COV outbreak in 2014 in Jeddah, Saudi Arabia (Khalid et al., 2016) was the reason for designing this questionnaire. Considering the similar nature of stressors, the second section of the questionnaire was used in the study. This section describes 20 factors that can cause stress among the nurses and is named MERS-COV stressors; the researcher named COVID-19 stressors since this study is related to the COVID-19 pandemic. First of all, respondents need to answer the statements in yes or no to state whether they felt stressed handling COVID-19 patients. Those marked yes needs to clarify the severity of the impacts. To identify the severity of the impact, statements to be rated from $0=$ very nominal to $3=$ very much. All 452 respondents have answered in affirmative that they have encountered situations that have caused stress; Cronbach's alpha of the sample is 0.861.

\section{Leader-member exchanges (LMX)}

The satisfaction of nurses with the quality of their supervisor-subordinate relationship was measured using an adapted seven-item unidimensional scale (LMX-7), which was developed by Graen and Uhl-Bien (1995). The reliability analysis showed a Cronbach's alpha of 0.879 .

Team-member exchanges (TMX)

The ten-item TMX quality scale developed by Seers et al. (1995) was used to measure the team-members' perception about the reciprocal exchange relationship between themselves and team members. It is a 5-point scale starting from 1 (strongly disagree) to 5 (strongly agree) was used. The alpha reliability of the scale was 0.858 .

Figure 1.

Hypothetical model

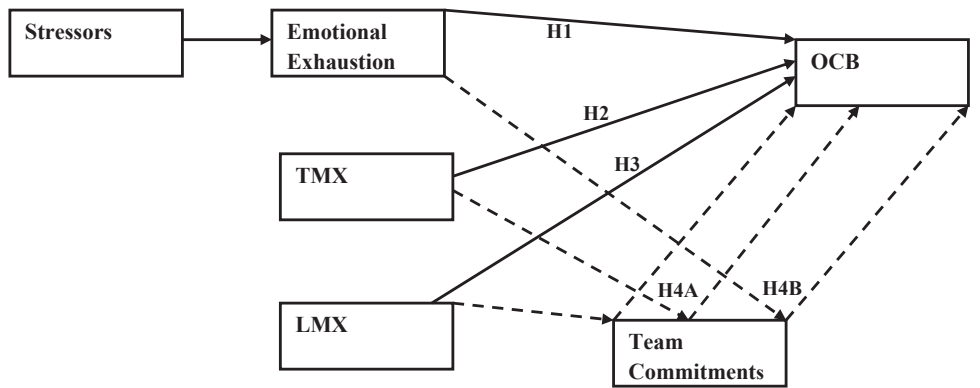


Team commitments

A seven-item scale (Ellemers et al., 1998) was used $(1=$ strongly disagree and $7=$ strongly agree). The Cronbach's alpha found was 0.878 .

\section{Emotional exhaustion}

Nine items were marked for the emotional exhaustion component from Maslach et al. (1996) adopted. It is a seven-Point Scale where (0) indicates (never) and (6) as (every day). The Cronbach's alpha found was 0.921 .

\section{Analytic strategy}

The study used statistical package for the social sciences (SPSS) 20 Version and Sobel test for data analysis and $p<0.05$ considered statistically significant. SPSS expressed the descriptive measures and investigated relations through correlation and regression analysis. The bootstrap model of regression analysis was applied to find the impact of mediation on a larger sample. Sobel test used to analyze whether the product of unstandardized regression coefficients of the regression analysis of independent, mediating and dependent variables are significant.

\section{Results}

\section{Participant characteristics}

Respondent nurses were within the range of 20-31 years with an average age of 25.2. They were within the experience of 1-5 years with an average experience of 2.6 years, and all were attending COVID-19 patients. Out of 452 Nurses, 325 were diploma in nursing and 127 were graduates and postgraduates in nursing.

\section{Descriptive statistics}

Descriptive statistics showed LMX (mean: 4.19; standard deviation (SD): 0.6 and range: 1.86 to 5); TMX (mean: 4.2, SD: 0.49 and range: 2 to 5); COVID-19 stressors (mean: 1.96, SD: 0.374 and range: 1 to 2.8); emotional exhaustion (mean: 2.18, SD: 1.57 and range: 0.00 to 5.78); team commitments (mean: 5.83; SD: 0.99 and range: 1.71 to 7) and OCB (mean: 4.71; SD: 0.99 and range: 1.57 to 6$)$.

Skewness and kurtosis analysis of data demonstrate all variables other than team commitment skewness is $>1$ and kurtosis $>2$; it indicates that the data are within the normality limit. Only team commitments show skewness -1.237 with standard error 0.115 and kurtosis 2.035 with a standard error of 0.229 .

\section{Relationship between the variables}

Correlation analysis indicated significant relationship between LMX and OCB $(r 0.363$, $p<0.01)$; TMX and OCB $(r 0.389, p<0.01)$; team commitments and OCB $(r 0.551, p<0.01)$; stressors negatively relates to OCB $(r-0.173, p<0.01)$ and emotional exhaustion also negatively relates to OCB $(r-0.191, p<0.01)$.

Correlation analysis showed a significant relationship between LMX and team commitments $(r$ 0.382, $p<0.01)$; TMX and team commitments $(r 0.448, p<0.01)$ and a negative relationship between emotional exhaustion and team commitments $(r-0.255$, $p<0.01)$. A significant relationship exists between nurses' stressors and emotional exhaustion $(r 0.666, p<0.01)$.

Hypotheses were tested in the order as follows:

$H 1$ stressors regressed on emotional exhaustion, where adjusted $R^{2} 0.442$, beta 0.666 , $p<0.01$ shows a significant relationship. Emotional exhaustion regressed on $\mathrm{OCB}$, where adjusted r sq 035 , beta $-0.191, p<0.01$ showed a negative relationship;
OCB of nurses in COVID-19 pandemic 
IRJMS

1,2

H2 TMX regressed on OCB, where adjusted $R^{2} 0.149$, beta $389, p<0.01$ showed the significant relationship, and TMX caused variance on OCB;

H3 LMX regressed on OCB, where adjusted $R^{2} 0.130$, beta $0.363, p<0.01$ showed the significant relationship and LMX influenced OCB of the nurses.

To investigate the mediation effect of team commitments on the relationship between emotional exhaustion, LMX and TMX with OCB regression were conducted based on the principle of Baron and Kenny (1986). They outlined fulfilling the following four conditions that establish mediation Baron and Kenny (1986):

(1) The independent variable must affect the mediator in the first equation significantly;

(2) The independent variable must affect the dependent variable in the second equation significantly;

(3) The mediator must affect the dependent variable in the third equation significantly and

(4) If these conditions meet, then the effect of the independent variable on the dependent variable must be lesser in the third equation than in the second.

In the case of perfect mediation, independent variable holds no effect on the dependent variable and mediating variable controls.

$H 4 A$ TMX regressed on team commitment, where adjusted $R^{2} 0.201$, beta $0.450, p<0.01$

TMX in the earlier test showed a significant relationship with OCB was regressed on it along with team commitment and showed beta $0.178, p<0.01$, which indicated the strength of the relationships reduced from beta 0.389 to 0.178 . Hence, team commitments partially mediate the relationship between TMX and OCB.

LMX regressed on team commitments, where adjusted $R^{2} 0.148$, beta $0.387, p<0.01$.

Team commitment regressed on OCB, where adjusted $R^{2} 0.302$, beta $0.551, p<0.01$ showed significant relations.

In the previous test, LMX displayed strong relationships with OCB and regressed with team commitment. Results are beta $0.179, p<0.001$ and it showed that beta reduced from $0.363, p<0.001$ to $0.179, p<0.01$ indicated partial mediation by team commitments.

$H 4 B$ emotional exhaustion regressed on team commitments, where adjusted $R^{2} 0.063$, beta $-0.255, p<0.01$ showed a negative relationship.

The last test showed a negative relationship between emotional exhaustion and OCB (beta $-0.191, p<0.01$ ) and regressed it along with team commitment on OCB; the result showed that beta -0.054 , sig $183, p>0.05$ indicates an insignificant relationship between emotional exhaustion and OCB. Team commitments maintained their original significant relationship (beta 0.538, sig 000). The relationship between emotional exhaustion and OCB turned to be insignificant when mediated by team commitments and was significant when emotional exhaustion acts alone; this indicates that team commitments fully mediated the relationship between emotional exhaustion and OCB.

These have been compiled in Table 1

$\mathrm{H} 4 \mathrm{~A}$ and $\mathrm{H} 4 \mathrm{~B}$ were investigated further through the bootstrap model on a sample of 5,000 to ascertain the indirect effect of team commitments in the relationship between TMX, LMX and emotional exhaustion on OCB of the nurses and then followed by the Sobel test to find the significance of the mediation effect.

The relationship between TMX and OCB mediated by team commitments $(b 0.360$, standard error 0.088 and $t 4.107$ from $b 0.789$, standard error 0.088 and $t 8.950$ ) showed a 


\begin{tabular}{|c|c|c|c|c|c|c|}
\hline IV & DV & MV & $\operatorname{Adj} R$ sq & Beta & Significance & OCB of nurses \\
\hline TMX & $\mathrm{OCB}$ & & 0.149 & 0.389 & $0.000 * *$ & pandemic \\
\hline LMX & $\mathrm{OCB}$ & & 0.130 & 0.363 & $0.000 * *$ & \\
\hline Stressors & $\mathrm{EE}$ & & 0.442 & 0.666 & $0.000 * *$ & \\
\hline Stressors & $\mathrm{OCB}$ & & 0.028 & -0.173 & $0.000 * *$ & \\
\hline $\mathrm{EE}$ & $\mathrm{OCB}$ & & 0.035 & -0.191 & $0.000 * *$ & \\
\hline TC & $\mathrm{OCB}$ & & 0.302 & 0.551 & $0.000 * *$ & 153 \\
\hline TMX & $\mathrm{TC}$ & & 0.199 & 0.448 & $0.000 * *$ & \\
\hline LMX & $\mathrm{TC}$ & & 0.144 & 0.382 & $0.000 * *$ & \\
\hline TMX & $\mathrm{OCB}$ & $\mathrm{TC}$ & 0.326 & 0.178 & $0.000 * *$ & \\
\hline LMX & $\mathrm{OCB}$ & $\mathrm{TC}$ & 0.328 & 0.178 & $0.000 * *$ & \\
\hline $\mathrm{EE}$ & $\mathrm{TC}$ & & 0.063 & -0.255 & $0.000 * *$ & \\
\hline $\mathrm{EE}$ & $\mathrm{OCB}$ & $\mathrm{TC}$ & 0.304 & -0.054 & 0.183 & $\begin{array}{l}\text { I able } 1 . \\
\text { Regression analysis }\end{array}$ \\
\hline \multicolumn{6}{|c|}{$* * p<0.01$ and $* p<0.05$} & (mediation analysis) \\
\hline
\end{tabular}

reduction in the impact. CI at $95 \%$ from 0.385 to 0.555 showed the influence team commitments exerted on the relationship between TMX and OCB. Sobel test conducted $(z=3.831, p<0.001)$ confirmed the mediation.

Relation between LMX and OCB intervened by team commitments $(b 0.289$, standard error $068, t 4.258$ reduced from $b 0.590$, standard error $0.071, t 8.255)$ showed a decrease in the influence of LMX on OCB. CI at 95\% from 0.400 to 0.563 showed the extent of impact team commitments exerted in the relationship between IV and DV. Sobel test result $(z=3.984$, $p<0.001$ ) supported the mediation analysis.

Results corroborated with the findings of multiple linear regression method $(b-0.034$, standard error. $026, t-1.335$, sig $183, p>0.05$ ) indicated an insignificant relationship between emotional exhaustion and OCB when intervened by team commitments and CI at $95 \%$ showed the indirect effect in the range of $0.456-615$. The direct relationship between emotional exhaustion and OCB was significant $(b-0.121$, standard error $029, t-4.138$, sig 000). It showed complete mediation of the effect of emotional exhaustion on OCB of the nurses by their team commitments; Sobel test result $(z=-1.301, p<0.001)$ concluded the mediation result.

Details are in Table 2.

The study proves that $\mathrm{H} 1, \mathrm{H} 2, \mathrm{H} 3$ and $\mathrm{H} 4 \mathrm{~B}$ are conclusive and $\mathrm{H} 4 \mathrm{~A}$ partially proved.

The tested model is in Figure 2.

\section{Discussion and implications}

The study examined the mediation effect of team commitments on the relationship between emotional exhaustion and OCB for nurses handling COVID-19 patients. Similarly, the study explored the mediation effect of team commitments on the relationships of LMX and TMX on OCB of the nurses. This study identified the COVID-19-related stressors that lead to emotional exhaustion and hinder the generation of OCB; the author found how team commitments interfere in the process to neutralize the impact on OCB. Social support at the workplace is considered a facilitating factor. Here, the study tried to explore how the support of members of the work unit and immediate supervisor facilitate the display of OCB and the role of team commitments in the process.

\section{Theoretical implications}

The study contributes to the literature in some ways. First, the mediation of the impact of emotional exhaustion on OCB of the nurses by team commitments and partial mediation of 


\section{IRJMS \\ 1,2}

Mediation analysis through bootstrap model (bootstrapping and Sobel test analysis)

\begin{tabular}{|c|c|c|c|c|c|c|c|}
\hline DV & IV & $b$ & SE & $t$ & Sig & Bootstrap 95\% CI & Sobel test $Z$ \\
\hline \multirow[t]{3}{*}{$\mathrm{OCB}$} & Constant & 1.398 & 0.372 & 3.754 & 0.000 & & \\
\hline & TMX & 0.789 & 0.088 & 8.950 & 0.000 & & \\
\hline & $\mathrm{TC}$ & 0.549 & 0.039 & 14.021 & 0.000 & & \\
\hline \multirow[t]{2}{*}{$\mathrm{TC}$} & Constant & 2.001 & 0.363 & 5.515 & 0.000 & & \\
\hline & TMX & 0.912 & 0.086 & 10.616 & 0.000 & & \\
\hline \multirow[t]{3}{*}{$\mathrm{OCB}$} & Constant & 0.457 & 0.342 & 1.336 & 0.182 & $0.385-0.555$ & $3.831 p<0.001$ \\
\hline & TMX & 0.360 & 0.088 & 4.107 & 0.000 & & \\
\hline & Indirect effect I & 0.470 & 0.043 & 10.919 & 0.000 & & \\
\hline \multirow[t]{3}{*}{$\mathrm{OCB}$} & Constant & 2.240 & 0.302 & 7.416 & 0.000 & & \\
\hline & LMX & 0.590 & 0.071 & 8.255 & 0.000 & & \\
\hline & $\mathrm{TC}$ & 0.549 & 0.039 & 14.021 & 0.000 & & \\
\hline \multirow[t]{2}{*}{$\mathrm{TC}$} & Constant & 3.216 & 0.304 & 10.691 & 0.000 & & \\
\hline & LMX & 0.624 & 0.071 & 8.777 & 0.000 & & \\
\hline \multirow[t]{3}{*}{$\mathrm{OCB}$} & Constant & 0.692 & 0.297 & 2.329 & 0.02 & $0.400-0.563$ & $3.984 p<0.001$ \\
\hline & LMX & 0.289 & 0.068 & 4.258 & 0.000 & & \\
\hline & Indirect effect II & 0.481 & 0.042 & 11.572 & 0.000 & & \\
\hline \multirow[t]{3}{*}{$\mathrm{OCB}$} & Constant & 4.971 & 0.078 & 63.472 & 0.000 & & \\
\hline & $\mathrm{EE}$ & -0.121 & 0.029 & -4.138 & 0.000 & & \\
\hline & $\mathrm{TC}$ & 0.549 & 0.039 & 14.021 & 0.000 & & \\
\hline \multirow[t]{2}{*}{$\mathrm{TC}$} & Constant & 6.181 & 0.077 & 79.775 & 0.000 & & \\
\hline & $\mathrm{EE}$ & -0.162 & 0.029 & -5.601 & 0.000 & & \\
\hline \multirow[t]{3}{*}{$\mathrm{OCB}$} & Constant & 1.663 & 0.259 & 6.424 & 0.000 & $0.456-0.615$ & $-1.301 p<0.001$ \\
\hline & $\mathrm{EE}$ & -0.034 & 0.026 & -1.335 & 0.183 & & \\
\hline & Indirect effect III & 0.535 & 0.040 & & & & \\
\hline
\end{tabular}

\section{$(\mathrm{t}-\mathbf{4 . 1 3 8 * * )}$}

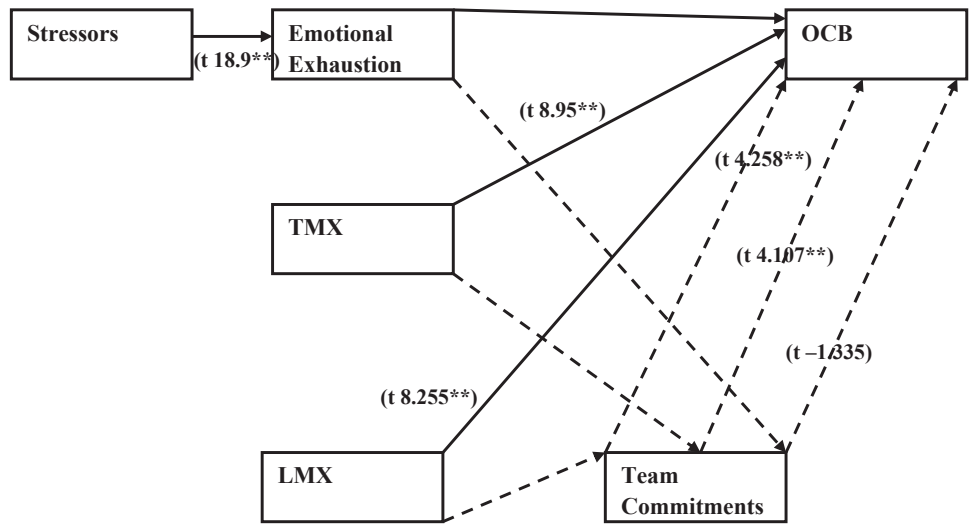

Figure 2.

Tested model
Note(s): ${ }^{* *} P<0.001 ; \longrightarrow$ Indicates Direct Relationship; $--\rightarrow$ Indicates Mediated Relationship

the relationship between TMX and LMX with OCB of the nurses caring COVID-19-infected patients is an addition to the organizational behavior literature. Performance of OCB is essential considering the burden on healthcare setup when COVID-19 is in the rise and emotional exhaustion dimension due to the stressors from handling COVID-19 patients is 
having a hindering effect. Study of such mediation effect through team commitments on the performance of OCB to COVID-19 patients despite the adverse impact of emotional exhaustion is rare.

Second, this study gets support from Lawler (2010); relational cohesion theory states that positive exchange among the people staying in proximity develops a sense of commitment to each other. This commitment makes one extend help or perform for others when the need arises; this study has provided a deeper understanding of the concept of relational commitments and empirically established its role in neutralizing the negative impact of emotional exhaustion on the OCB of nurses.

Third, the complete mediation effect of team commitments in the influence of emotional exhaustion on the extra-role behavior of nurses indicates the dominance of service to superordinate goals of the care unit (Caricati, 2015) over the personal difficulty of the nurses. These have implications in nursing literature and show the spirit of the nurses in serving humanity.

Fourth, the mediation effect of team commitments on positive LMX-TMX-OCB relationships contributes to the literature; it is a fact that employees' positive social experience at the workplace promotes their emotional and attitudinal responses and results in positive job behavior. It aligns with the attitude-behavior sequence of relationships (Zhao et al., 2007; Agarwal and Gupta, 2015).

\section{Managerial implications}

The study has important managerial implications. Overload of patients and shortage of nurses in pandemic situations have caused pressure on the healthcare system where the voluntary performance of nurses can serve as a means to tide over the situations to some extent (Sharif-Nia et al., 2021). Emotional exhaustion acts as a detriment to OCB; team commitments of the nurses found in the study as a neutralizing factor and can be encouraged by the hospital managers.

Studies (e.g. Murat et al., 2020; Parel et al., 2020) reported a high level of emotional exhaustion and burnout of nurses attending COVID-19 patients. Even this study observed the high stress of some nurses caring for COVID-19 patients.

Murat et al. (2020) recommended coping mechanisms of nurses by hospital managers. Support at the workplace in the form of positive exchange with leaders and team members evokes positive emotion at work and may serve as a coping mechanism; healthcare managers can encourage repetition of this behavior in the daily transaction of the unit members.

Additionally, team commitments that bring affiliation with the team need to be promoted in the pandemic when nurses are not even in a situation to converse regularly with their family members. In such circumstances, commitment to team members and the team brings a feeling of security from oneness and sharing the same boat.

\section{Study limitations and scope for further research}

In this study, nurses have displayed higher than moderate stress levels (1.97 on a scale of 0 3 ), though some of them showed to be very much stressed 2.8. This result might have happened as the data were collected from January 7 to April 8, 2021 when nurses underwent COVID-19 vaccination. Moreover, 2nd spell of COVID-19 was not prominent in Kolkata till that time, but 30 respondent nurses who participated in 1st week of April reported higher stress (2.3) when 2nd spell started hitting Kolkata. Parel et al.'s (2020) study on Indian nurses found depression, anxiety and stress were higher among nurses treating COVID-19 patients than others. Their survey was from March 26, 2020 to April 8, 2020 when India was locked down. Kar et al.'s (2021) comparative study on stress and anxiety disorder arising out of COVID-19 between the general public and healthcare workers reported less anxiety, 
IRJMS

1,2

depression and stress of healthcare workers. They attributed this finding to the higher level of information, better preparedness and confidence in preventing the infection of the healthcare workers (Kar et al., 2021). There are differences in the findings of Kar et al. (2021) and Parel et al. (2020). It can be a subject of further research as a longitudinal study will provide better insight.

The study did not investigate the effect of gender, age and experience on stress level and emotional exhaustion of the nurses handling COVID-19 patients. Murat et al. (2020) observed mean emotional exhaustion was significantly higher in male nurses. They identified that nurses with experience of less than a year were more stressed than their senior counterparts (Murat et al., 2020). Zhang et al. (2020) found female nurses handling COVID-19 patients are higher in stress and depression. About Indian nurses, no such study seems to be available, and one can undertake further research.

This study focused on the effect of the social aspect of the nurses at the workplace, work stress and the mediation effect of team commitments on their OCB. A point that deserves consideration here is patient care of the units is dependent also on professionals like doctors and technicians who may need to exhibit OCB in dealing with a large load of COVID-19 patients. A comprehensive study encompassing all these professionals will give a broader picture and here lies the scope for further research.

\section{Conclusion}

COVID-19 has caused havoc on the healthcare system of the entire world. Nurses took care of the COVID-19 patients, and due to the infectious nature of the virus, many got infected. In presence of a large number of COVID-19 patients and a shortage of nurses, their workload increased significantly. With a heavy workload, nurses need to take care of these patients keeping in abeyance the fear of infection and several other stressors identified in the literature. COVID-19 situation has also compelled nurses to perform some exercises not present in their job description. As the pandemic is lasting for a long time, nurses deliver care continuously to COVID-19 patients in this stressful situation. All these might lead to the emotional exhaustion of the nurses.

This study explored the influence of emotional exhaustion arising out of unmanaged stress of nurses in handling COVID-19-infected patients on their extra-role behavior and mediating effects of team commitments on it. Healthy LMX and TMX create team commitments of nurses that may significantly impact the relationship between emotional exhaustion and OCB of nurses.

Hypotheses designed have been proved, and team commitments have fully mediated the negative relationship between emotional exhaustion and OCB of nurses; team commitment has partially mediated the relationship between LMX, TMX and OCB. Mediation exercise was undertaken by following the principles suggested by Baron and Kenny using the multiple regression method. Sobel test and bootstrapping analysis analyzed the mediation on a larger sample. All these confirmed reliability of the tests.

\section{References}

Agarwal, U. and Gupta, V. (2015), "Examination of a moderated-mediation model linking perceived organizational support, affective commitment”, Organizational Citizenship Behavior and Work Engagement: A Study of Nurses in the Indian Context. W.P. No. 2015-03-05, IIMA Institutional Repository, pp. 1-32, available at: http://hdl.handle.net/11718/16624.

Alshaabani, A., Naz, F., Magda, R. and Rudnák, I. (2021), "Impact of perceived organizational support on OCB in the time of COVID-19 pandemic in Hungary: employee engagement and affective commitment as mediators", Sustainability, Vol. 13 No. 14, p. 7800, doi: 10.3390/su13147800. 
Bakker, A.B. and Demerouti, E. (2007), "The job demands-resources model: state of the art", Journal of Managerial Psychology, Vol. 22 No. 3, pp. 309-328, doi: 10.1108/02683940710733115.

Baron, R.M. and Kenny, D.A. (1986), "The moderator-mediator variable distinction in social psychological research: conceptual, strategic, and statistical considerations", Journal of Personality and Social Psychology, Vol. 51 No. 6, pp. 1173-1182, doi: 10.1037//0022-3514.51.6.1173.

Bishop, J.W. and Scott, K.D. (2000), "An examination of organizational and team commitment in a self-directed team environment”, Journal of Applied Psychology, Vol. 85 No. 3, pp. 439-450, doi: 10.1037//0021-9010.85.3.439.

Bishop, J., Scott, K. and Burroughs, S. (2000), "Support, commitment, and employee outcomes in a team environment", Journal of Management, Vol. 26 No. 6, pp. 1113-1132, doi: 10.1016/S01492063(00)00083-0.

Caricati, L., Guberti, M., Borgognoni, P., Prandi, C., Vezzani, E. and Lemmi, M. (2015), "The role of professional and team commitment in nurse-physician collaboration: a dual identity model perspective", Journal of Inter-professional Care, Vol. 29 No. 5, pp. 464-468, doi: 10.3109/ 13561820.2015.1016603.

Che, X., Guo, Z. and Chen, Q. (2021), "The relationship between K-workers' leader-member exchange, organizational citizenship behavior and task performance - evidence from Chinese hospitals", Frontiers in Psychology, Vol. 12, p. 625584, doi: 10.3389/fpsyg.2021.625584.

Cropanzano, R., Anthony, E.L., Daniels, S.R. and Hall, A.V. (2017), "Social exchange theory: a critical review with theoretical relevance", The Academy of Management Annals, Vol. 11 No. 1, pp. 1-38, doi: 10.5465/annals.2015.0099.

Dasgupta, P. (2020), "Effect of organizational support, leader-member exchange, team-member exchange and the effect of mediation by affective and team commitments on the organizational citizenship behavior of nurses”, IUP Journal of Organizational Behavior, Vol. 19 No. 2, pp. 27-54, search.proquest.com.

Ellemers, N., Gilder, D. and Heuvel, H.V.D. (1998), "Career versus team commitment \& behavior at work”, Journal of Applied Psychology, Vol. 83 No. 5, pp. 717-730.

Ellemers, N., Kortekaas, P. and Ouwerkerk, J.W. (1999), "Self-categorisation, commitment to the group and group self-esteem as related but distinct aspects of social identity", European Journal of Social Psychology, Vol. 29, pp. 371-389, doi: 10.1002/(SICI)1099-0992(199903/05)29:2/33.3.CO;2-L.

Götz, M., Donzallaz, M. and Jonas, K. (2020), "Leader-Member exchange fosters beneficial and prevents detrimental workplace behavior: organizational identification as the linking pin", Frontiers in Psychology, Vol. 11, p. 1788, Published online 2020 Aug 18, doi: 10.3389/fpsyg.2020.01788.

Graen, G.B. and Uhl-Bien, M. (1995), "Relationship-based approach to leadership: development of leader-member exchange (LMX) theory of leadership over 25 Years: applying a multi-level, multi-domain perspective", Leadership Quarterly, Vol. 6 No. 2, pp. 219-247, doi: 10.1016/10489843(95)90036-5.

Kar, N., Kar, B. and Kar, S. (2021), "Stress and coping during COVID 19 pandemic: result of an Onlinesurvey”, Psychiatry Research, Vol. 295 No. 113598, pp. 1-6, doi: 10.1016/j.psychres.2020.113598.

Khalid, I., Khalid, T.J., Qabajah, M.R., Barnard, A.G. and Qushmaq, I.A. (2016), "Healthcare workers emotions, perceived stressors and coping strategies during a MARS-COV outbreak", Clinical Medicine and Research, Vol. 14 No. 1, pp. 7-14, doi: 10.3121/cmr.2016.1303.

Lawler, E.J. (2010), "Relational cohesion theory (Electronic Version)", in Levine, J.M. and Hogg, M.A. (Eds), Encyclopedia of Group Processes and Intergroup Relations, Sage Publications, Thousand Oaks, CA, pp. 690-691, doi: 10.4135/9781412972017.n211.

Lawler, E.J., Thyes, S.R. and Yoon, J. (2000), "Emotion and group cohesion in productive exchange", American Journal of Sociology, (Faculty Publication No. 11-2000), Sociology Department, the University of Chicago, Vol. 106 No. 3, pp. 616-657.

Lee, R.T. and Ashforth, B.E. (1993), "A further examination of managerial burnout: towards an integrated model”, Journal of Organizational Behavior, Vol. 14, pp. 3-20, doi: 10.1002/job.4030140103.

OCB of nurses in COVID-19 pandemic 
IRJMS 1,2

Leiter, M.P. and Maslach, C. (1988), "The impact of inter-personal environment on Burnout and Organizational commitment”, Journal of Organizational Behavior, Vol. 9 No. 4, pp. 297-308, doi: 10.1002/job.4030090402.

Maslach, C., Jackson, S.E. and Leiter, M.P. (1996), Maslach Burnout Inventory Manual, 3rd ed., Consulting Psychologists Press, Palo Alto, CA.

Murat, M., Kose, S. and Savaser, S. (2020), "Determination of stress, depression and burnout levels of front line nurses during the COVID 19 pandemic", International Journal of Mental Health Nursing, Vol. 30 No. 2, pp. 533-543, doi: 10.1111/inm.12818.

Neininger, A., Lehmann-Willenbrock, N., Kauffeld, S. and Henschel, A. (2010), "Effects of team and organizational commitment - a longitudinal study", Journal of Vocational Behavior, Vol. 76, pp. 567-579, (2010), doi: 10.1016/j.jvb.2010.01.009.

Organ, D.W. (1988), Organisational Citizenship Behavior: the Good Soldier Syndrome, Lexington Books, Lexington, MA.

Padgett, S.M. (2013), "Professional collegiality and peer monitoring among nursing staff: an Ethnographic study", International Journal of Nursing Studies, Vol. 50 No. 10, pp. 1407-1415, doi: 10.1016/j.ijnurstu.2012.12.022.

Parel, J.T., Varshney, M., George, M., Khurana, R., Thomas, L. and Khakha, D.C. (2020), "Feeling the early impact of COVID-19 pandemic: mental health of nurses in India", Journal of Depression and Anxiety, Vol. 9 No. 6, pp. 1-6, doi: 10.35248/2167-1044.20.9.381.

Podsakoff, P.M., Mackenzie, S.B., Moorman, R.H. and Fetter, R. (1990), "Transformational leader behaviors and their effects on followers' trust in leader, satisfaction and organizational citizenship behaviors", Leadership Quarterly, Vol. 1 No. 2, pp. 107-142, doi: 10.1016/10489843(90)900097.

Riketta, M. and Van Dick, R. (2005), "Foci of attachment in organizations: a meta- analytic comparison of the strength and correlates of workgroup versus organizational identification and commitment", Journal of Vocational Behavior, Vol. 67 No. 3, pp. 490-510, doi: 10.1016/j.jvb.2004.06.001.

Said, R.M. and El-Shafei, D.A. (2020), "Occupational stress, job satisfaction, and intent to leave: nurses working in front lines during COVID 19 pandemic in Zagazig City, Egypt", Environmental Science and Pollution Research, Vol. 28, on-Line 8791-8801, doi: 10.1007/11356-020-11235-8.

Santarone, K., McKenny, M. and Elkbuli, A. (2020), "Preserving mental health and resilience in front line healthcare workers during COVID 19", American Journal of Emergency Medicine, Vol. 38 No. 7, pp. 1530-1531, doi: 10.1016/j.ajem.2020.04.030.

Scheepers, D. and Ellemers, N. (2019), "Social identity theory", in Sassenberg, K. and Vliek, M.L.W. (Eds), Social Psychology in Action: Evidence Based Interventions from Theory to Practice, Leiden University Scholarly Publications, pp. 129-143, doi: 10.1007/978-3-030-13788-5_9.

Schreuder, F., Schalk, R. and de Jong, J. (2017), "Psychological contracts in self-directed work teams: development of a validated scale and its effects on team commitment: team Performance Management”, An International Journal, Vol. 23 Nos 3-4, doi: 10.1108/TPM-07-2016-0035.

Seers, A., Petty, M. and Cashman, J.F. (1995), "Team-Member exchange under team and traditional management", Group and Organization Management, Vol. 20 No. 1, pp. 18-38, doi: 10.1177/ 1059601195201003.

Sharif Nia, H., Arslan, G., Naghavi, N., Sivarajan Froelicher, E., Kaveh, O., Pahlevan Sharif, S. and Rahmatpour, P. (2021), "A model of nurses' intention to care of patients with COVID-19: mediating roles of job satisfaction and organisational commitment", Journal of Clinical Nursing, Vol. 30 Nos 11-12, pp. 1684-1693, doi: 10.1111/jocn.15723.

Sharma, R.P., Pohekar, S.B. and Ankar, R.S. (2020), "Role of a nurse in COVID 19 pandemic", Journal of Evolution of Medical and Dental Science, Vol. 9 No. 35, pp. 2550-2555, doi: 10.14260/jemds/ 2020/554.

Shreffler, J., Petrey, J. and Huecker, M. (2020), "The impact of covid 19 on healthcare worker wellness: a scoping review", Western Journal of Emergency Medicine, Vol. 21 No. 5, pp. 1059-1066, doi: 10.5811/westjem.2020.7.48684. 
Tajfel, H. (1978), "Social categorization, social identity and social comparison", in Tajfel, H. (Ed.), Differentiation between Social Groups: Studies in the Social Psychology of Intergroup Relations, Academic Press, London, pp. 61-76.

Van Dyne, Graham, J. and Dienesch, R.M. (1994), "Organizational citizenship behavior: construct redefinition, measurement, and validation”, Academy of Management Journal, Vol. 37 No. 4, pp. 765-802, doi: 10.5465/256600.

Wu, P., Liu, X. and Fang, Y. (2008), "Alcohol abuse/dependence symptoms among hospital employees exposed to a SARS outbreak", Alcohol and Alcoholism, Vol. 43 No. 6, pp. 706-712, doi: 10.1093/ alcalc/agn073.

Zhang, L., Jiang, H. and Jin, T. (2020), "Leader-member exchange and organisational citizenship behaviour: the mediating and moderating effects of role ambiguity", Journal of Psychology in Africa, Vol. 30 No. 1, pp. 17-22, doi: 10.1080/14330237.2020.1721948.

Zhang, H., Zhao, Y., Zou, P., Lin, S., Mu, S., Deng, Q., Du, C., Zhou, G., Wu, J. and Gan, L. (2021), "Explaining organizational citizenship behavior among Chinese nurses combating COVID 19", Risk Management and Healthcare Policy, Vol. 14, pp. 979-986, doi: 10.2147/RMHP.S292436.

Zhao, H.A.O., Wayne, S.J., Glibkowski, B.C. and Bravo, J. (2007), "The impact of psychological contract breach on work-related outcomes: a meta-analysis", Personnel Psychology, Vol. 60 No. 3, pp. 647-680, doi: 10.1111/j.1744-6570.2007.00087.x.

\section{Further reading}

Staff Reporter (2021), "Healthcare Workers under Stress as many test positive in Bihar", The Times of India, available at: https:/timesofindia.indiatimes.com/city/patna/healthcare-workers-understress-as-manytest-ve/articleshow/82234699.

\section{Corresponding author}

Prasanjit Dasgupta can be contacted at: pdasgupta2015@gmail.com

For instructions on how to order reprints of this article, please visit our website:

www.emeraldgrouppublishing.com/licensing/reprints.htm

Or contact us for further details: permissions@emeraldinsight.com 